University of Nebraska - Lincoln

DigitalCommons@University of Nebraska - Lincoln

Sociology Department, Faculty Publications

Sociology, Department of

2001

\title{
The Impact of Childhood Sexual Abuse on Later Sexual Victimization among Runaway Youth
}

\author{
Kimberly A. Tyler \\ University of Nebraska-Lincoln, kim@ktresearch.net \\ Dan R. Hoyt \\ University of Nebraska-Lincoln, dhoyt2@unl.edu \\ Les B. Whitbeck \\ University of Nebraska-Lincoln, Iwhitbeck2@unl.edu \\ Ana Mari Cauce \\ University of Washington
}

Follow this and additional works at: https://digitalcommons.unl.edu/sociologyfacpub

Part of the Sociology Commons

Tyler, Kimberly A.; Hoyt, Dan R.; Whitbeck, Les B.; and Cauce, Ana Mari, "The Impact of Childhood Sexual Abuse on Later Sexual Victimization among Runaway Youth" (2001). Sociology Department, Faculty Publications. 38.

https://digitalcommons.unl.edu/sociologyfacpub/38

This Article is brought to you for free and open access by the Sociology, Department of at DigitalCommons@University of Nebraska - Lincoln. It has been accepted for inclusion in Sociology Department, Faculty Publications by an authorized administrator of DigitalCommons@University of Nebraska - Lincoln. 


\title{
The Impact of Childhood Sexual Abuse on Later Sexual Victimization among Runaway Youth
}

\author{
Kimberly A. Tyler \\ University of Nebraska-Lincoln
}

\author{
Dan R. Hoyt and Les B. Whitbeck \\ Iowa State University \\ Ana Mari Cauce \\ University of Washington
}

\begin{abstract}
Path analysis was used to investigate the impact of childhood sexual abuse on later sexual victimization among 372 homeless and runaway youth in Seattle. Young people were interviewed directly on the streets and in shelters by outreach workers in youth service agencies. High rates of both childhood sexual abuse and street sexual victimization were reported, with females experiencing much greater rates compared with their male counterparts. Early sexual abuse in the home increased the likelihood of later sexual victimization on the streets indirectly by increasing the amount of time at risk, deviant peer affiliations, participating in deviant subsistence strategies, and engaging in survival sex. These findings suggest that exposure to dysfunctional and disorganized homes place youth on trajectories for early independence. Subsequently, street life and participation in high-risk behaviors increases their probability of sexual victimization.
\end{abstract}

The number of children who experience childhood sexual abuse has sharply increased in recent years. According to the third national inci-

Requests for reprints should be sent to Kimberly A. Tyler, Department of Sociology, 711 Oldfather Hall, University of Nebraska-Lincoln, Lincoln, NE 68588-0324. 
dence study of child abuse and neglect (Sedlak \& Broadhurst, 1996), over 300,000 children were sexually abused in 1993. This figure has more than doubled since the last national incidence study, which represents a 125\% increase (Sedlak \& Broadhurst, 1996). Although rates of sexual abuse tend to vary by study, the pattern is for high prevalence rates. For example, Finkelhor and Dziuba-Leatherman (1994) found rates of abuse as high as 25\% among their sample of 10- to 16-year-olds. Studies on homeless and runaway youth have found rates of sexual abuse that exceed 50\% (Janus, McCormack, Burgess, \& Hartman, 1987; Silbert \& Pines, 1981).

Gender has been found to be a risk factor associated with sexual abuse. The third national incidence study of child abuse and neglect (Sedlak \& Broadhurst, 1996) reported that females were sexually abused about three times more often than males. The greater risk of sexual abuse for females tends to be stable over time (Sedlak \& Broadhurst, 1996). Similarly, Kellogg and Hoffman (1997) found that $54 \%$ of females reported having experienced sexual victimization compared with $15 \%$ of males. Studies of runaways also have revealed much higher rates of sexual abuse among females compared with males (McCormack, Janus, \& Burgess, 1986; Whitbeck \& Simons, 1990).

\section{THE EFFECTS OF EARLY SEXUAL ABUSE}

Many adolescents who experience childhood sexual abuse suffer negative developmental outcomes. Some of the short-term effects include depression, low self-esteem, running away, substance abuse, promiscuity, anger, hostility, inappropriate sexual behavior, and internalizing and externalizing problems (Beitchman, Zucker, Hood, da Costa, \& Akman, 1991; Browne \& Finkelhor, 1986; Kendall-Tackett, Williams, \& Finkelhor, 1993; Trickett \& Putnam, 1998). Some research also suggests that the devastating consequences of maltreatment may not show up until several years later in the form of antisocial or self-destructive behavior (Eckenrode, Powers, \& Garbarino, 1997). Therefore, some argue that sexual abuse should be viewed as a repeated trauma that typically occurs over an extended period of time, because the psychological effects can manifest themselves in numerous areas, resulting in low self-esteem, anxiety, poor social relationships, delinquency, and substance abuse (Eckenrode et al., 1997; KendallTackett et al., 1993; Putnam \& Trickett, 1993). The long-term effects of early sexual abuse have included promiscuity, depression, difficulty trusting others, self-destructive behavior, and revictimization (Beitchman et al., 1992; Browne \& Finkelhor, 1986). 


\section{RUNAWAY AND HOMELESS YOUTH}

Considering the high rates of sexual abuse that many runaway adolescents have experienced (Janus et al., 1987; McCormack et al., 1986; Silbert \& Pines, 1981), it should be no surprise that many of them run as a result of the abuse (Cauce et al., 1998; Gutierres \& Reich, 1981; Terrell, 1997; Whitbeck \& Simons, 1990). As indicated by Janus and associates (1987, p. 17), ". . these youths are running from something, not running to something." Understanding the trajectories of homeless and runaway youth who have experienced early sexual abuse is particularly salient because previous research has found a link between childhood abuse and revictimization on the streets (Whitbeck, Hoyt, \& Ackley, 1997a; Whitbeck \& Simons, 1990). The current study examines the pathways that exist between childhood sexual abuse and street sexual victimization using a risk amplification model (Whitbeck, Hoyt, \& Yoder, 1999).

\section{RISK AMPLIFICATION MODEL}

The risk amplification model, developed by Whitbeck and colleagues (Whitbeck et al., 1999), provides a way to understand the life histories of these adolescents. This perspective accounts for why young people are on the streets and why they engage in the particular lifestyles and daily routines that they do once they are out there. This model, which draws from life course developmental theory (Elder, 1998) and social interaction theory (Patterson, 1982), suggests that adolescents exposed to dysfunctional and disorganized homes are placed on trajectories for early independence. Once adolescents reach the streets they become affiliated with deviant peers, which leads to their involvement in risky, deviant behaviors, thereby increasing their risk for sexual victimization (Whitbeck et al., 1999). Affiliation with deviant peers can be explained by the coping styles and coercive and abusive behaviors that these adolescents have learned in their family of origin.

Patterson has argued that coercive families provide "basic training" for antisocial behaviors (Patterson, Dishion, \& Bank, 1984). This first or basic training is the result of continuous failure on the part of the parents to use effective discipline techniques to control coercive exchanges between family members. Through this training, the child learns to control other members of the family by means of coercion, and these interaction styles are generalized into other contexts. These coercive and abusive behaviors become coping styles that are carried with the adolescent into peer interactions, which results in rejection by normal friend groups (Patterson, 
DeBaryshe, \& Ramsey, 1989; Patterson et al., 1984). Children who learn to expect rejection may withdraw from future interactions, thereby ruling out opportunities to affiliate with prosocial peers and, therefore, never having the opportunity to practice conventional social skills (Moffitt, 1993).

The coercive and abusive behavior patterns learned in the family become self-reinforcing, resulting in the selection and creation of environments that are familiar and congruent with these interaction styles. These persistent behavioral patterns are continually reinforced in interactions with others, a process Caspi and colleagues (Caspi, Bem, \& Elder, 1987) have termed "cumulative continuity." Therefore, adolescents who grow up in families that display aggressive and antisocial behaviors are likely to become members of social groups that display similar characteristics. This reflects a continuous course of antisocial behavior throughout the life course and has been termed "life-course persistent" (Moffitt, 1993). As adolescents leave or are thrown out of their dysfunctional families, interaction patterns learned at home are carried into early independence. The "basic training" for antisocial behavior in the family becomes "advanced training" on the streets (Whitbeck et al., 1999).

In summary, many adolescents who experience family abuse are likely to run from home (Gutierres \& Reich, 1981). Once on the streets, the combination of antisocial behavior and rejection by conventional peers leads adolescents to form ties with deviant peer groups, which are important for explaining adolescents' subsequent involvement in risky, deviant behaviors (Whitbeck et al., 1997a; Whitbeck et al., 1999). Knowing the life histories of these adolescents makes it easier to understand the choices they make while on the streets. When resources are few and choices are extremely limited, the social context of street life-in which the end result for many of these homeless adolescents is often victimization-can be overwhelming.

\section{HYPOTHESIZED MODEL}

A fully recursive model was hypothesized to investigate the cumulative effects of caretaker sexual abuse (Figure 1). Abuse in the home has been linked to runaway behavior (Farber, Kinast, McCoard, \& Falkner, 1984; Gutierres \& Reich, 1981; Silbert \& Pines, 1982). Because childhood sexual abuse typically occurs between 8 and 12 years of age (Finkelhor, 1984), children who have been abused sexually are likely to run at earlier ages. Therefore, it was expected that early sexual abuse would be negatively associated with the age at which adolescents first left home (Figure 1, Arrow A). A history of family abuse has been found to be associated with running 


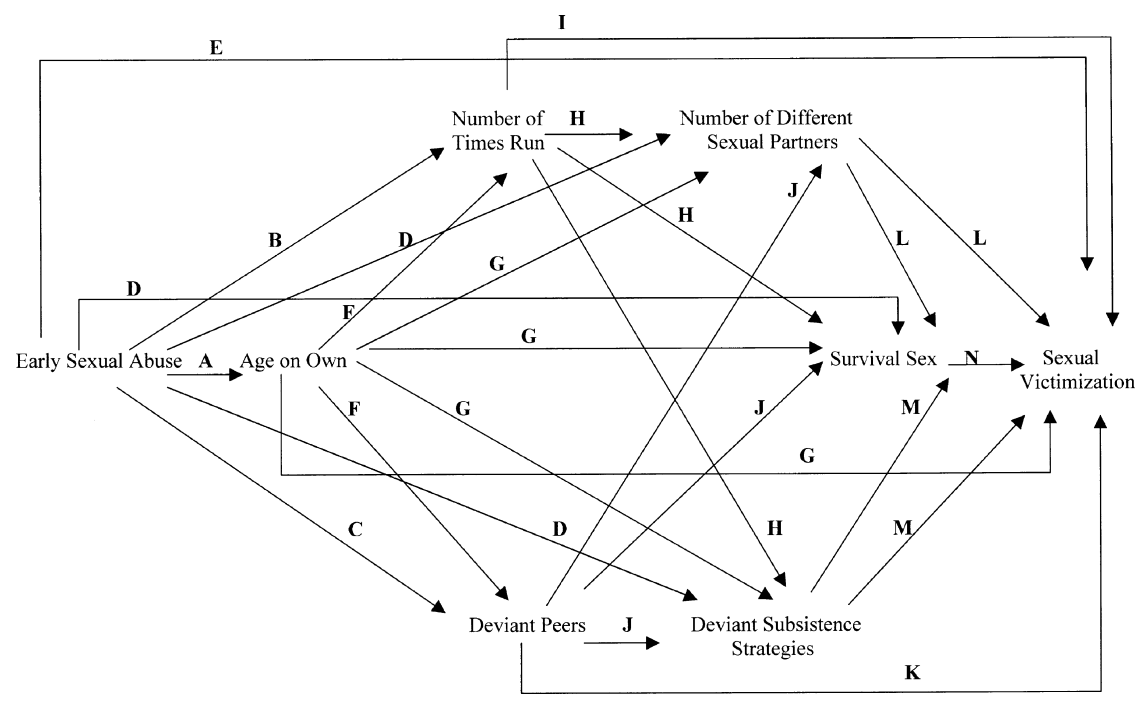

FIGURE 1 Hypothesized model for male and female sexual victimization.

away numerous times and spending time on the streets (Janus et al., 1987; Whitbeck \& Simons, 1990). Janus and colleagues (1987) noted that many runaways were from dysfunctional families with little support available and oftentimes go in search of a better life. Whitbeck and Simons (1990) also found that homeless adolescents who had been abused were multiple runaways, and, therefore, likely to spend more time on their own. Following this, it was hypothesized that early sexual abuse would be positively related to the number of times that adolescents ran away (Arrow B).

Research has found that adolescents who experienced higher rates of family abuse were more likely to affiliate with nonconventional peers (Silbert \& Pines, 1982; Whitbeck et al., 1997a; Whitbeck \& Simons, 1990). For example, Silbert and Pines (1982) found that adolescents from abusive backgrounds were rejected by friends in the early grades, and those who made friends during high school typically formed relationships with friends who were involved in some form of deviancy. Therefore, a positive association was hypothesized between early sexual abuse and deviant peers (Arrow C). A number of studies have linked abuse by parents to numerous sexual partners (Bagley \& Young, 1987), deviant subsistence strategies (McCormack et al., 1986; Whitbeck \& Simons, 1990), and survival sex (Silbert \& Pines, 1981). Based on these findings, direct, positive effects also were hypothesized for early sexual abuse on number of different sexual 
partners, deviant subsistence strategies, and survival sex (Arrows D). Finally, adolescents from abusive backgrounds often experience more emotional problems, such as depression, anxiety, and poor self-esteem, compared with their nonabused counterparts (Beitchman et al., 1991; Eckenrode et al., 1997; Kendall-Tackett et al., 1993; Morrow \& Sorell, 1989), which may make them more vulnerable targets on the streets. Accordingly, early sexual abuse was hypothesized to directly influence sexual victimization (Arrow E).

It is plausible that children who leave home at a young age have very limited resources. Therefore, they may develop a pattern whereby they return home for a brief period and then run again. In addition, spending more time on the streets increases the opportunity for runaways to form ties with deviant peers and to engage in criminal street networks (Hagan \& McCarthy, 1997; Whitbeck \& Hoyt, 1999). As such, youth who run for the first time at an early age were expected to run away numerous times and to affiliate with deviant peers (Arrows F). Further, being homeless and spending time on the street cultivates involvement in deviant subsistence strategies (Hagan \& McCarthy, 1997; Whitbeck \& Hoyt, 1999). Runaway and homeless youth who spent more time on their own reported being offered money for sex (Janus et al., 1987). With few legitimate means of support, many runaways resort to survival sex or are sometimes coerced into the sex trade by pimps (Silbert \& Pines, 1981; Weisberg, 1985). In addition, studies also have found high rates of sexual activity among homeless youth as well as a high number of different sex partners (Kipke, O'Connor, Palmer, \& MacKenzie, 1995; Rotheram-Borus et al., 1992). Since being on the streets for longer time periods increases exposure and risk, it was hypothesized that the age at which youth were on their own would be associated with number of different sexual partners, deviant subsistence strategies, survival sex, and sexual victimization (Arrows $G$ ).

Youth who run from home numerous times are likely to spend more time on the streets, which is associated with participation in deviant subsistence strategies (Hagan \& McCarthy, 1997; Whitbeck \& Hoyt, 1999), engaging in sex trade (Janus et al., 1987; McCarthy \& Hagan, 1992; Weisberg, 1985), and having numerous sexual partners (Kipke et al., 1995). Because it increases the amount of time at risk for participation in risky behaviors, a positive association was predicted between the number of times youth run and number of different sexual partners, deviant subsistence strategies, and survival sex (Arrows $\mathrm{H}$ ). Victimization also has been found to be associated with the amount of time spent in public places, especially at night (Hindelang, Gottfredson, \& Garofalo, 1978), because being on the streets exposes youth to dangerous people and places. Therefore, it was expected that the number of times youth run would positively predict sexual victimization (Arrow I). 
Runaways who associate with deviant peers have been found to engage in similar high-risk behaviors (Hagan \& McCarthy, 1997; Kipke, Unger, O'Connor, Palmer, \& LaFrance, 1997; Whitbeck et al., 1999). For example, Kipke and colleagues (1997) note that street peers provide guidance and instruction that aid youth in surviving on the streets. The results of their study revealed that affiliation with peers strongly influenced the behavior of homeless youth such that those who associated with hustlers were more likely to rely on prostitution to support themselves financially (Kipke et al., 1997). Runaway and homeless youth also have been found to have high participation rates of survival sex and prostitution (Rotheram-Borus et al., 1992). Since homeless youth spend much of their time hanging out with other street youth (Yates, MacKenzie, Pennbridge, \& Cohen, 1988), and are influenced by the behaviors of such youth (Kipke et al., 1997), it is likely that this will affect adolescents' decision to engage in similar activities. Studies also have found that runaways who associate with deviant peers are more likely to engage in risky sexual behaviors (Whitbeck et al., 1999). Therefore, a positive association was expected between deviant peers and number of different sexual partners, deviant subsistence strategies, and survival sex (Arrows J). Finally, it was hypothesized that deviant peers would positively predict sexual victimization (Arrow K), because deviant peer affiliation is significantly related to being a victim of sexual assault (Terrell, 1997).

Runaways who report numerous sexual partners are more likely to engage in survival sex (Kipke et al., 1995). Engaging in sexual intercourse with numerous partners is also associated with being a victim of sexual assault (Abbey, Ross, McDuffie, \& McAuslan, 1996). Based on a situational vulnerability hypothesis, it is believed that frequent dating and sexual activity increases the chances that a woman will eventually interact with a man who is willing to force her into unwanted sex (Abbey et al., 1996). Following this, numerous sexual partners was expected to be associated with engaging in survival sex and being a victim of sexual assault (Arrows $L$ ).

Homeless and runaway youth who engage in deviant subsistence strategies are highly visible in the street environment and are at risk for being taken advantage of by potential offenders. For example, pimps have been found to use coercion, physical force, flattery, and the promise of money to persuade female runaways to become prostitutes (Weisberg, 1985). Engaging in deviant subsistence strategies such as robbing and conning also has been found to further increase risk for victimization (Lauritsen, Sampson, \& Laub, 1991). Accordingly, it was hypothesized that participation in deviant subsistence strategies would be positively associated with survival sex and sexual victimization (Arrows M). Finally, selling sex puts adolescents in dangerous and vulnerable situations. Female adolescents who trade sex 
suffer violence at the hands of their customers, pimps, and other street people (Weisberg, 1985). Therefore, survival sex was expected to positively predict sexual victimization (Arrow N). The model also controlled for the effects of gender, age, and race.

\section{Procedure}

\section{METHOD}

Data are from the Seattle Homeless Adolescent Research and Education Project (SHARE). It has been well established that it is not possible to randomly sample homeless populations (Wright, Allen, \& Devine, 1995) since unbiased enumeration is not realistic. Therefore, young people were interviewed using a systematic sampling strategy that maximized locating homeless and runaway youth in metropolitan Seattle. This strategy employed both street intercepts and locale interviewing. The locales, which provided homeless youth with services, were contacted to obtain permission to give interviewers access to youth. Young people were interviewed over a period of 2 years (February 1996 to February 1998) by outreach workers who were trained youth workers with considerable experience in interviewing and interacting with this group of young people. They were very familiar with local street cultures and were already known and trusted by many of the runaways. Interviewers approached all available youth who passed through or were at the locale and appeared to be between the ages of 13 and 21. Street intercepts were made by approaching youth in the areas of the city known to be frequented by homeless and runaway adolescents. These street intercept interviews were conducted at numerous coffee houses, restaurants, other inside areas such as libraries and cafeterias, the respondent's residence, and outside, if weather permitted. In addition to solicitations by the interviewers, youth also were recruited through flyers posted in the local agencies and group informational meetings held at the agencies.

Youth were first administered a brief "eligibility" interview. If deemed to be eligible, the study and procedures were explained and informed consent was obtained from interested youth. Eligible youth were between 13 and 21 years of age, spoke English, and did not, at the time of the interview, have a stable residence or a viable home to which they could return, and were not physically in the custody of the state. Unstable residence was further defined and constrained as not living with parents or guardians in the previous week and not having spent more than 4 nights at home in the past week. Youth staying at foster care or who were temporarily housed with family were considered eligible. Also, youth not living in a group 
home for 45 days or more, or having the potential to stay in a group home for more than 45 days were considered eligible. If the youth had been on the streets less than 1 week, parental permission was obtained prior to the interview. In the state of Washington, adolescents can be considered emancipated at the age of 13. In addition to meeting this age criterion, however, youth were considered emancipated only if they were judged as having no significant contact with parents, including no longer being financially dependent on them, and did not spend any time at home for a week prior to the interview. If the youth met all these criteria, they were considered emancipated and were allowed to provide sole consent.

Respondents were informed that they could refuse participation, refuse single questions, or stop participating in the interview at any time. If young people agreed to participate and complete the consent forms, interviewers took the youth to a quiet, private location to conduct the interview. Due to the length of the questionnaire, the interview was conducted in two parts on separate days. Each section took approximately $1 \frac{1 / 2}{2}$ to 2 hours to complete. The youth were paid $\$ 10$ for each section with a $\$ 5$ bonus for completing both sections. Thus, they were offered $\$ 25$ for the entire completed interview. This study was approved by the Institutional Review Board at the University of Washington. The overall response rate was $95 \%$.

\section{Participants}

A total of 372 adolescents were interviewed. Just over half were male 203 $(54.6 \%)$ and 169 were female $(45.4 \%)$. The age of these young people at the time of the interview ranged from 12 to 21 years with a median of 17 years for the total sample. In terms of race, $48 \%$ were White, $6 \%$ were African American, 5\% were Native American, 3\% were Hispanic, and 2\% were Asian or Pacific Islander. Thirty-six percent of the sample considered themselves biracial or multiracial.

\section{Measures}

It should be noted that the terms sexual abuse and sexual victimization throughout the remainder of the article refer to contact episodes only.

Early sexual abuse was measured using a four-item scale that focused on contact sexual abuse that the young person may have experienced while living at home (adapted from Whitbeck \& Simons, 1990). For example, "Has an adult or someone at least 5 years older than you ever had you do something sexual", "kissed or touched you sexually", and "put or tried to 
put anything or any part of their body into you sexually?" Due to skewness of the individual items, each indicator was dichotomized $(0=$ never, $1=$ at least once). A count procedure was then done to delete missing cases and a composite measure of early sexual abuse was created. Cronbach's $\alpha$, which is a measure of internal consistency and an estimate of reliability (Carmines \& Zeller, 1979), was .89, which was very similar to the value reported by Whitbeck and Simons (1990).

Age at first run was measured by a single item that asked adolescents how old they were when they left home for the first time. Many adolescents were on their own for the first time at a very young age. However, it is possible that the early incidents of leaving home (i.e., under age 6) could be related to the child being removed by protective services. The mean age at first run was 13.3 years for the total sample.

Number of times run was measured by a single item that asked respondents the total number of times they had ever run away from home. The number of times that adolescents had run away ranged from 1 to over 98 times with a mean of 9.5 runs. Seventy-four percent of the total sample reported running 10 times or less.

Deviant peers was measured using a 13-item scale that asked young people if any of their close friends had ever engaged in deviant behaviors such as selling drugs, using drugs, selling sex, and threatening or assaulting someone with a weapon (Whitbeck \& Simons, 1990). The response categories for each of the items was $0=$ no and $1=$ yes. A count procedure was performed on the 13 items to delete missing cases. The composite scale ranged from 0 to 13 . Cronbach's $\alpha$ for deviant peers was .87 .

Number of different sexual partners was an indicator variable that asked participants the total number of different people with whom they had engaged in sex in the past 12 months. Due to skewness at the high end of the variable, this item was divided into three categories: $0=$ no sexual partners in the past year; $1=$ one or two sexual partners in the past year; and $2=$ three or more sexual partners in the past year. Each of the three categories had approximately an equal number of respondents.

Deviant subsistence strategies was measured using six items that focused on different tactics that adolescents may have used in order to survive since being on the streets (Whitbeck \& Simons, 1990). Respondents were asked to indicate how often they shoplifted, conned, robbed someone, sold drugs, mugged someone, and broke into a store or house to take things. Due to skewness of the individual items, each indicator was dichotomized ( $0=$ never, $1=$ at least once) and then a count procedure was done to form a scale of deviant subsistence strategies. Cronbach's $\alpha$ was .73, a value very similar to the one reported by Whitbeck and Simons (1990).

Survival sex consisted of seven items that measured whether adoles- 
cents had ever traded sex to obtain the things they needed since being on their own. The first six items focused on whether young people had ever traded sex for specific items such as food, shelter, or money. A count procedure was performed and a dichotomous measure was created where $0=$ never traded sex for any specific item and $1=$ have traded sex for a specific item. The final indicator, which measured how often the adolescent traded sex, was dichotomized ( $0=$ never, $1=$ at least once $)$ and a count procedure was done to delete missing cases. The next step included taking these two single dichotomous measures and summing them to form a composite measure of survival sex. Due to the skewness of this variable, survival sex was dichotomized into $0=$ never traded sex and $1=$ have traded sex at least once. The final composite measure revealed that $11 \%$ of respondents had traded sex for one reason or another. Cronbach's $\alpha$ was .76.

Sexual victimization consisted of four items that focused on whether respondents had any unwanted or unpleasant sexual experiences with people since they had been on their own (adapted from Whitbeck \& Simons, 1990). For example, "Has anyone forced you to do something sexual" and "Has anyone had you touch them sexually when you didn't want to?" Due to skewness, a dichotomous measure of sexual victimization was created $(0=$ never been sexually victimized, $1=$ have been sexually victimized). Cronbach's $\alpha$ for sexual victimization was .78.

\section{RESULTS}

The adolescents in the current study experienced high levels of sexual abuse prior to running away. Overall, $22 \%$ of the total sample experienced some form of contact sexual abuse. Young women were twice as likely to be victims of sexual abuse compared with young men (30\% versus $15 \%$, respectively). Of those who were abused, more than one third (39\%) indicated that the sexual abuse was extremely violent. Rates of extremely violent sexual abuse also tended to be higher among females (43\%) compared with males $(31 \%)$.

Adolescents were asked four questions that focused on early sexual experiences that they may have had with an adult or someone at least 5 years older before they were on their own. Table 1 shows the percentages for each of the sexual abuse items for the total sample, females, and males. The percentage for each item indicates that such an incident occurred at least once. Twenty percent of the total sample indicated that they had been forced to do something sexual at least once; the corresponding rates among females and males, respectively, were $29 \%$ and $12 \%$. Females were likely to experience higher rates for each of the abuse items listed. 
TABLE 1

Percentage Who Experienced Sexual Abuse by Gender

\begin{tabular}{lccc}
\hline & $\begin{array}{c}\text { Total } \\
(N=309)\end{array}$ & $\begin{array}{c}\text { Female } \\
(N=144)\end{array}$ & $\begin{array}{c}\text { Male } \\
(N=165)\end{array}$ \\
\hline $\begin{array}{l}\text { Has an adult ever . . } \\
\quad \text { had you do something sexual? }\end{array}$ & 20.0 & 28.8 & 12.2 \\
had you touch them sexually? & 14.9 & 17.5 & 12.7 \\
kissed / touched you sexually? & 20.5 & 29.5 & 12.7 \\
$\quad$ tried to put any part of their body into you sexually? & 11.7 & 16.2 & 7.9 \\
\hline
\end{tabular}

Not only had these young people experienced high rates of early sexual abuse but many also experienced sexual victimization. The percentage of youths who experienced sexual victimization since being on their own are shown in Table 2. The percentage for each item indicates that such an incident had occurred at least once. For every category listed, females were more likely to have experienced sexual victimization compared with their male counterparts. Overall, $36 \%$ of the total sample indicated that they had experienced some form of contact sexual victimization.

The Pearson correlation coefficients, $r$, for the measures used in these analysis are presented in Table 3. Due to listwise deletion of missing cases, 351 youth were included in these analyses. Significant correlations ranged from .11 to .51 . Means, standard deviations, and ranges for all variables also are included.

Results of the path analysis are shown in Figure 2 (only significant paths are shown). Because some of the variables were dichotomous, this model was estimated using the weighted least squares procedure in LISREL VIII (Joreskog \& Sorbom, 1993). Thus, each of the standardized path coefficients, $\beta$, for arrows leading to a specific dependent variable were estimated simultaneously with all other variables predicted to influence the

TABLE 2

Percentage Who Have Been Sexually Victimized since Being on the Streets by Gender

\begin{tabular}{lccr}
\hline & $\begin{array}{c}\text { Total } \\
(N=358)\end{array}$ & $\begin{array}{c}\text { Female } \\
(N=162)\end{array}$ & $\begin{array}{c}\text { Male } \\
(N=196)\end{array}$ \\
\hline $\begin{array}{l}\text { Has an adult ever . . } \\
\text { had you do something sexual? }\end{array}$ & 28.9 & 48.1 & 12.8 \\
had you touch them sexually? & 11.0 & 18.0 & 5.1 \\
kissed / touched you sexually? & 30.7 & 48.1 & 16.3 \\
tried to put any part of their body into you? & 19.8 & 34.6 & 7.7 \\
\hline
\end{tabular}




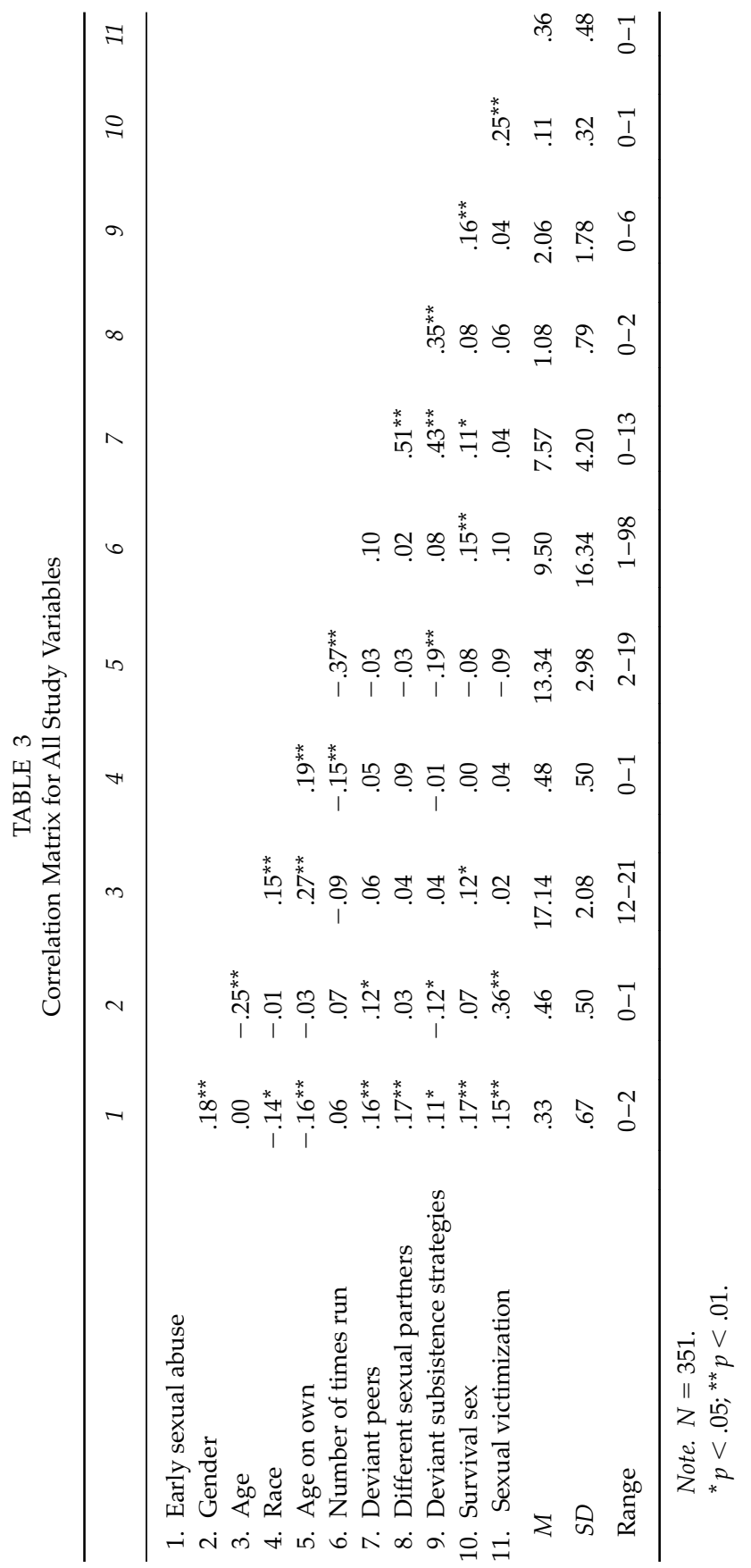




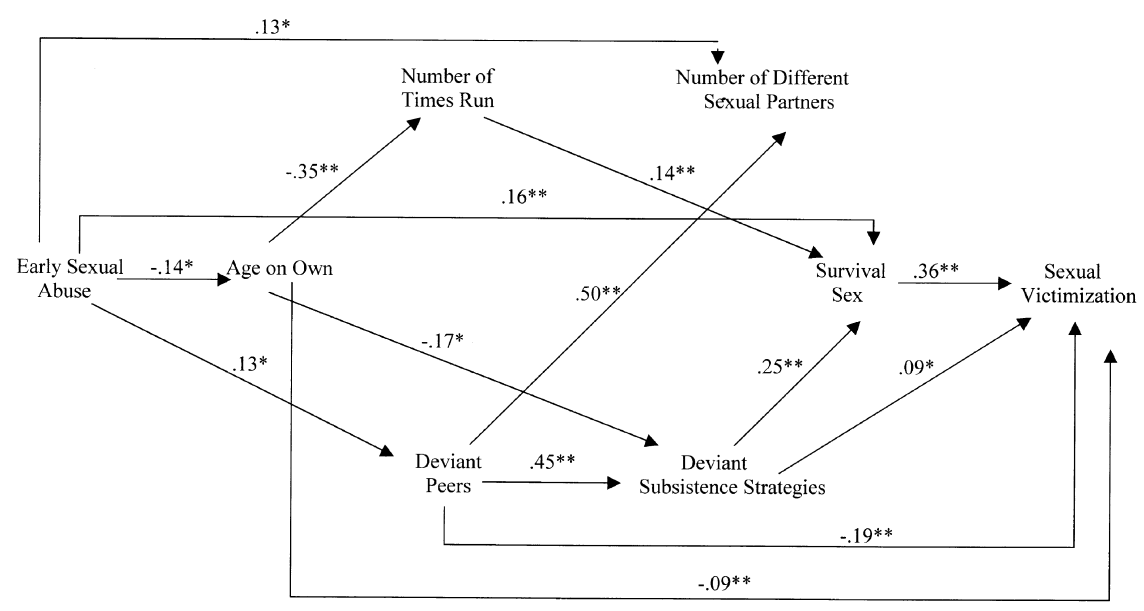

FIGURE 2 Path model for male and female sexual victimization (only significant paths shown). $R^{2}=.52 .{ }^{*} p<.05 ;{ }^{* *} p<.01$.

measure in question. This is a fully saturated model that fits the data perfectly; therefore, fit indices are not reported.

The model revealed that early sexual abuse was negatively associated with age on own, $\beta=-.14, p<.05$, indicating that adolescents who experienced more abuse were likely to run from home at early ages. A history of sexual abuse also was positively associated with deviant peers, $\beta=.13$, $p<.05$, survival sex, $\beta=.16, p<.01$, and number of different sexual partners, $\beta=.13, p<.05$, suggesting that youth who experienced more sexual abuse were likely to affiliate with deviant peers, trade sex, and report numerous sexual partners out on the streets.

Age on own was negatively associated with deviant subsistence strategies, $\beta=-.17, p<.05$, number of times run, $\beta=-.35, p<.01$, and sexual victimization, $\beta=-.09, p<.01$, which indicates that young people who ran from home at early ages were more likely to have run away numerous times, to have participated in more deviant subsistence strategies, and to have been sexually victimized. Running away numerous times was positively related to survival sex, $\beta=.14, p<.01$. Deviant peers was associated with number of different sexual partners, $\beta=.50$, $p<.01$, deviant subsistence strategies, $\beta=.45, p<.01$, and sexual victimization, $\beta=-.19, p<.01$. Young people who engaged in various forms of deviant subsistence strategies were more likely to have traded sex, $\beta=.25, p<.01$, and to have been sexually victimized, $\beta=.09, p<$ 
.05. Finally, those who sold sex were more likely to have been victims of sexual assault, $\beta=.36, p<.01$.

Controlling for the effects of gender revealed that males were more likely to have engaged in various forms of deviant subsistence strategies, $\beta=-.25$. In contrast, females were more likely to have sold sex, $\beta=.22$, and been sexually victimized, $\beta=.60$. Controlling for the effects of age revealed that older respondents were more likely to have traded sex, $\beta=.29$, and to have been sexually victimized, $\beta=.16$. Finally, in terms of race, Whites were more likely to run from home at later ages, $\beta=.17$, compared with non-Whites. A test for interactions revealed that the different paths leading to sexual victimization did not differ significantly by gender, age, or race. The model explained $52 \%$ of the variance in the sexual victimization variable.

The decomposition of the effects of independent variables on the dependent variable (Joreskog \& Sorbom, 1993) are presented in Table 4. The results indicated that all of the effects of early sexual abuse on later sexual victimization were indirect. Early sexual abuse indirectly affected later sexual victimization via age on own, number of times run, deviant peers, deviant subsistence strategies, and survival sex. In addition to having a direct effect on sexual victimization, age on own also had an indirect effect through number of times run, deviant subsistence strategies, and survival sex. The effects of number of times run on sexual victimization were indirect through survival sex. Deviant peers had an indirect effect on sexual victimization via deviant subsistence strategies and survival sex, but also had a direct effect. Deviant subsistence strategies had both a direct influence on sexual victimization and an indirect effect through survival sex. Finally, survival sex directly influenced sexual victimization.

\section{DISCUSSION AND CONCLUSIONS}

Consistent with the work of others (Cauce et al., 1998; Janus et al., 1987; McCormack et al., 1986), the current study revealed that of the runaway youth interviewed, many had experienced childhood sexual abuse, with females reporting much higher rates compared with their male counterparts. Many young people in this study also experienced various forms of sexual victimization on the streets. Relative to young men, females experienced higher rates of every type of sexual victimization, which is congruent with previous research (Whitbeck \& Simons, 1990, 1993).

Overall, results from multivariate analyses revealed that early sexual abuse was directly related to age on own, deviant peers, number of different sexual partners, and survival sex. Sexual abuse was indirectly related 
TABLE 4

Decomposition of Effects for Male and Female Sexual Victimization

\begin{tabular}{|c|c|c|c|c|c|c|c|}
\hline & $\begin{array}{l}\text { Age on } \\
\text { Own }\end{array}$ & $\begin{array}{l}\text { Number } \\
\text { of Times } \\
\text { Run }\end{array}$ & $\begin{array}{l}\text { Deviant } \\
\text { Peers }\end{array}$ & $\begin{array}{l}\text { Different } \\
\text { Sexual } \\
\text { Partners }\end{array}$ & $\begin{array}{l}\text { Deviant } \\
\text { Subsistence } \\
\text { Strategies }\end{array}$ & $\begin{array}{l}\text { Survival } \\
\text { Sex }\end{array}$ & $\begin{array}{c}\text { Sexual } \\
\text { Victimi- } \\
\text { zation }\end{array}$ \\
\hline \multicolumn{8}{|c|}{ Early sexual abuse } \\
\hline Direct & $-.14^{*}$ & -.04 & $.13^{*}$ & $.13^{*}$ & .07 & $.16^{* *}$ & -.03 \\
\hline Indirect & .00 & .05 & .01 & $.07^{\star}$ & $.09^{* *}$ & $.05^{*}$ & $.09^{\star *}$ \\
\hline Total & $-.14^{*}$ & .01 & $.14^{* *}$ & $.20^{* *}$ & $.16^{*}$ & $.21^{* *}$ & .06 \\
\hline \multicolumn{8}{|l|}{ Gender } \\
\hline Direct & .08 & .09 & .16 & -.08 & $-.25^{* *}$ & $.22^{*}$ & $.60^{* *}$ \\
\hline Indirect & .00 & -.03 & .00 & .07 & .05 & -.05 & .01 \\
\hline Total & .08 & .07 & .15 & -.01 & $-.20^{*}$ & .17 & $.60^{* *}$ \\
\hline \multicolumn{8}{|l|}{ Age } \\
\hline Direct & $.26^{* *}$ & .06 & .11 & -.03 & -.02 & $.29^{\star \star}$ & $.16^{* *}$ \\
\hline Indirect & .00 & $-.09^{* *}$ & -.02 & .04 & .00 & -.04 & .05 \\
\hline Total & $.26^{* *}$ & -.04 & .10 & .01 & -.03 & $.25^{\star \star}$ & $.21^{* *}$ \\
\hline \multicolumn{8}{|l|}{ Race } \\
\hline Direct & $.17^{*}$ & -.12 & .08 & .11 & .01 & .02 & .07 \\
\hline Indirect & .00 & -.06 & -.01 & .04 & .00 & -.04 & -.03 \\
\hline Total & $.17^{*}$ & $-.18^{*}$ & .07 & .14 & .02 & -.01 & .05 \\
\hline \multicolumn{8}{|c|}{ Age on own } \\
\hline Direct & & $-.35^{\star *}$ & -.06 & -.02 & $-.17^{*}$ & -.09 & $-.09^{\star *}$ \\
\hline Indirect & & .00 & .00 & -.02 & -.02 & $-.10^{\star *}$ & $-.08^{* *}$ \\
\hline Total & & $-.35^{\star *}$ & -.06 & -.04 & $-.19^{\star \star}$ & $-.19^{* *}$ & $-.18^{* *}$ \\
\hline \multicolumn{8}{|c|}{ Number of times run } \\
\hline Direct & & & & -.03 & -.01 & $.14^{* *}$ & .01 \\
\hline Indirect & & & & .00 & .00 & .00 & $.05^{*}$ \\
\hline Total & & & & -.03 & -.01 & $.14^{*}$ & .06 \\
\hline \multicolumn{8}{|c|}{ Deviant peers } \\
\hline Direct & & & & $.50^{* *}$ & $.45^{* *}$ & -.03 & $-.19^{* *}$ \\
\hline Indirect & & & & .00 & .00 & $.11^{\star *}$ & $.10^{\star *}$ \\
\hline Total & & & & $.50^{* *}$ & $.45^{\star *}$ & .09 & $-.09^{*}$ \\
\hline \multicolumn{8}{|c|}{$\begin{array}{l}\text { Different sexual } \\
\text { partners }\end{array}$} \\
\hline Direct & & & & & & .00 & .06 \\
\hline Indirect & & & & & & .00 & .00 \\
\hline Total & & & & & & .00 & .06 \\
\hline \multicolumn{8}{|c|}{$\begin{array}{l}\text { Deviant subsistence } \\
\text { strategies }\end{array}$} \\
\hline Direct & & & & & & $.25^{\star *}$ & $.09^{*}$ \\
\hline Indirect & & & & & & .00 & $.09^{* *}$ \\
\hline Total & & & & & & $.25^{\star *}$ & $.18^{* *}$ \\
\hline \multicolumn{8}{|l|}{ Survival sex } \\
\hline Direct & & & & & & & $.36^{* *}$ \\
\hline Indirect & & & & & & & .00 \\
\hline Total & & & & & & & $.36^{* *}$ \\
\hline
\end{tabular}

${ }^{*} p<.05 ;{ }^{* *} p<.01$. 
to sexual victimization. Specifically, adolescents who experienced higher rates of early sexual abuse were likely to run from home at younger ages. It is possible that adolescents reach a certain threshold at which they can no longer tolerate the abuse and then run. Therefore, running away is seen as a coping mechanism or an adaptive response to dealing with sexual abuse (Garbarino, Wilson, \& Garbarino, 1986; Gutierres \& Reich, 1981). Because childhood sexual abuse typically occurs between 8 and 12 years of age (Finkelhor, 1984), it seems likely that younger children who experience higher rates of sexual abuse are at higher risk for running away.

As hypothesized, early sexual abuse was positively related to deviant peers. This finding is consistent with the theoretical model whereby coercive and abusive interaction styles learned within the family become selfreinforcing. Because of such interaction styles, adolescents are rejected by their normal peers (Patterson et al., 1984), thereby selecting into new environments that mimic old ones, such as deviant peer affiliations, which help to reinforce and amplify the negative developmental consequences that these youth suffered in their family of origin (Caspi et al., 1987; Whitbeck et al., 1999). In addition, existing in the street environment can be dangerous and risky at best. With few conventional ties, these young people are likely to associate with deviant peers whom they often depend on for protection and support (Hagan \& McCarthy, 1997). Further, as remarked by Silbert and Pines (1982, p. 497), "For an isolated, lonely girl, coming from a home marked by violence and abuse, the attraction of the deviant group, which provides her with a sense of belonging, is enormous."

Early sexual abuse was associated with number of different sexual partners, which is consistent with previous research (Bagley \& Young, 1987; Silbert \& Pines, 1982). Adolescents who suffer abuse are likely to have low self-esteem and high rates of depression and isolation (Beitchman et al., 1991; Eckenrode et al., 1997; Kendall-Tackett et al., 1993; Morrow \& Sorell, 1989). As such, they may become involved in numerous relationships, which provide them with the attention they desperately seek. For example, Silbert and Pines (1982) found that many of their respondents who had experienced sexual abuse were promiscuous because they wanted attention and wanted people to like them. Early sexual abuse also had a significant indirect effect on number of different sexual partners via deviant peers. In addition to the sexualized behavior in which many sexually abused adolescents engage (Beitchman et al., 1991; Kendall-Tackett et al., 1993), affiliation with deviant peers who participate in numerous antisocial behaviors (e.g., selling sex) and who exert a particularly strong influence in the lives of these youth (Kipke et al., 1997) may also account for the increased number of different sexual partners. 
Although early sexual abuse did not have a direct effect on deviant subsistence strategies, it did have a significant indirect effect through age on own. This suggests that the longer adolescents are on the streets, the more likely they are to resort to deviant subsistence strategies. There are few legitimate means of support for youth on the streets and the longer they remain in such an environment, the more likely they are to turn to various forms of deviant activities to support themselves. Deviant subsistence strategies were also influenced by early sexual abuse via deviant peers. Deviant peers have been found to serve as mentors and tutors who transmit skills and knowledge about criminal activity to other street youth (Hagan \& McCarthy, 1997). Therefore, affiliation with deviant peers may be responsible for other street youths' subsequent involvement in deviant subsistence strategies, which is consistent with other research on homeless and runaway youth (Hagan \& McCarthy, 1997; Whitbeck \& Hoyt, 1999).

Sexual abuse was associated with survival sex, which is consistent with the work of others (Bagley \& Young, 1987; Silbert \& Pines, 1982). Children who experience sexual abuse typically have been degraded and demoralized. This type of vulnerability makes them easy targets for predators who try and entice runaways into a life of prostitution (Bagley \& Young, 1987; Widom \& Kuhns, 1996). Sexual abuse also indirectly influenced survival sex via age on own, number of times run, deviant peers, and deviant subsistence strategies. Those who are on the streets at a young age are likely to form ties with other street youth for protection (Hagan \& McCarthy, 1997) and to engage in deviant subsistence strategies in order to survive. In addition, the negative self-concept that many of these young people bring to the streets as a result of early abuse may make them vulnerable targets for street predators. Moreover, for those who are hungry and need shelter, engaging in survival sex may be a last resort (Silbert \& Pines, 1981).

Finally, early sexual abuse had a significant indirect effect on later sexual victimization, which is consistent with other research on homeless and runaway youth (Whitbeck \& Simons, 1990). The negative developmental trajectories that many of these youth bring to the streets, in combination with running away at a young age, running away numerous times, deviant peer affiliations, engaging in deviant subsistence strategies, and survival sex increase the likelihood of sexual victimization. Consistent with a risk amplification model, adolescents learn antisocial behaviors within the family, which are carried with them into peer interactions, resulting in rejection by normal friend groups. Adolescents tend to select new environments for themselves that mimic old ones, thus leading to deviant peer affiliations. Associating with such peer groups and the necessity of surviving in the street environment result in adolescents' involvement in deviant, 
risky behaviors (e.g., deviant subsistence strategies and survival sex), which are associated with an increased risk for sexual victimization (Whitbeck et al., 1999).

Age on own was associated with running away numerous times. It is possible that younger adolescents have few resources available; therefore, they begin to lead a nomadic existence, shuffling back and forth from home to the streets (McCarthy \& Hagan, 1992). Those who run for the first time at a young age increase the length of time that they are at risk for running again. Therefore, the younger youth are at the time they first run, the more likely is the risk for running away numerous times.

No support was found for the link between age on own and deviant peers and number of different sexual partners. Although previous research has found high rates of sexual activity and multiple sex partners among homeless youth (Kipke et al., 1995; Rotheram-Borus et al., 1992), it appears that in the current study such outcomes are a result of experiencing early sexual abuse rather than the age at which the adolescent left home.

Age on own had a direct effect on deviant subsistence strategies. This finding is supportive of the current literature in that being homeless and spending time on the streets cultivates involvement in deviant subsistence strategies (Hagan \& McCarthy, 1997; Whitbeck \& Hoyt, 1999). It is likely that the more time youth spend on the streets, the greater their risk of becoming involved in deviant behaviors, which often provide a means of survival.

Age on own also had a significant indirect effect on survival sex through number of times run and deviant subsistence strategies. Adolescents who run away numerous times are likely to spend more time on their own, and being on the streets has been found to be associated with being offered money for sex (Janus et al., 1987). Youth who are exposed to the street environment are at risk of being coerced into the sex trade by pimps or other predators (Silbert \& Pines, 1981; Weisberg, 1985). In addition, those who are already engaging in criminal activities, such as selling drugs and mugging or conning people (i.e., deviant subsistence strategies), are at risk for coming into contact with potential offenders, which also may lead to involvement in prostitution and selling sex.

Finally, age on own had both a direct and indirect effect on sexual victimization. In terms of a direct effect, being on the streets at a young age is an important risk factor. It is possible that some of these young people are suffering from a negative self-image such as low self-esteem or high levels of depression, which may be a result of early sexual abuse. The combination of negative developmental outcomes and being on the streets at a young age may translate into a vulnerable situation in which they are likely to become targets of sexual victimization. In terms of indirect effects, existing in the street environment leads to participation in various forms 
of deviant behaviors (Hagan \& McCarthy, 1997; Whitbeck \& Hoyt, 1999). Because youth have been on the streets for longer time periods, they are likely to have participated in numerous deviant behaviors as a means of survival, many of which are often dangerous, thereby increasing their risk for sexual victimization.

Although Kipke and colleagues (1995) found an association between length of time homeless (which is associated with number of times run) and number of different sexual partners, no support was found for this hypothesis in the current study. This difference may be explained by the fact that early sexual abuse was taken into account in the current study and such abuse has been found to be a strong determinant of having numerous sexual partners (Bagley \& Young, 1987; Silbert \& Pines, 1982).

Number of times run had a direct effect on survival sex. Youth may initially leave home to escape abuse but with few resources available, may be forced to quickly return home. The abuse may repeat itself and young persons may flee again. Adolescents become involved in a viscous circle in which the only alternative to abuse at home may be life on the streets. Having made this decision, youth are forced to survive on their own. Trading sex for food, shelter, money, and drugs may be the only alternative for some youth. Furthermore, when they cannot return home and have no other place to go, selling sex may be their only option (cf. Silbert \& Pines, 1981).

An indirect effect was also found for number of times run on sexual victimization via survival sex. Running from home numerous times increases the amount of time that youth spend on the streets. Youth who spend more time on their own report being offered money for sex (Janus et al., 1987), and engaging in survival sex increases the risk for sexual victimization from customers and pimps (Weisberg, 1985).

Consistent with the literature, spending time with deviant peers was associated with an increase in the number of different sexual partners and participation in deviant subsistence strategies (Hagan \& McCarthy, 1997; Kipke et al., 1997; Whitbeck et al., 1999). Since homeless youth spend much of their time hanging out with other street youth (Yates et al., 1988), their deviant peers are likely to influence their behavior. Because of the lack of resources available to street youth, many engage in high-risk behaviors in order to survive. Therefore, if friends are participating in deviant behaviors, there is a good chance that these youth will engage in similar activities.

Deviant peers had a significant indirect effect on survival sex. It appears that associating with deviant peers leads to participation in deviant subsistence strategies, which in turn leads to survival sex. Runaway and homeless youth have high participation rates of survival sex and prostitution (Rotheram-Borus et al., 1992), and many of the youth in the current study 
reported having friends who sold sex. Since deviant peers have been found to serve as mentors or tutors for criminal street involvement and aid in street survival (Hagan \& McCarthy, 1997; Kipke et al., 1997), it is likely that associating with deviant peers will increase the chances of these youth engaging in similar activities. High participation rates in deviant subsistence strategies and selling sex increases visibility and vulnerability in the street environment, which leads to an increased risk for victimization.

Deviant peers had a direct effect on sexual victimization and an indirect effect via deviant subsistence strategies and survival sex. Contrary to what was expected, affiliation with deviant peers was negatively associated with sexual victimization. This suggests that those who affiliate with deviant peers are at lower risk for sexual victimization. One possible explanation for this finding is that their close friends act as a buffer against sexual victimization. Although these young people are likely to continue to be at risk, their street peers may provide some level of safety from this form of victimization. Focusing on perpetrators of street sexual victimization (which was beyond the scope of the current study), may shed some light on this issue. Finally, associating with deviant peers indirectly leads to sexual victimization. For example, selling drugs (i.e., deviant subsistence strategy) and selling sex expose young people to potential victimizers, thereby increasing their risk.

Although some research has found that runaways who report numerous sexual partners are more likely to engage in survival sex (Kipke et al., 1995) and are at higher risk for sexual victimization (Abbey et al., 1996), no support was found for either hypothesis in the current study. Instead, it appears that engaging in deviant subsistence strategies is a bigger risk factor for both survival sex and sexual victimization.

Engaging in deviant subsistence strategies had a direct effect on survival sex and sexual victimization. It is likely that homeless and runaway youth who engage in deviant subsistence strategies are highly visible, and spending time in public places is associated with personal victimization (Hindelang et al., 1978). Such exposure may result in these young people being preyed upon by pimps or other potential offenders who may use different methods to entice runaways into becoming prostitutes (Weisberg, 1985). Similarly, engaging in deviant subsistence strategies such as robbing and conning expose youth to a wide range of individuals and customers who themselves may be potential victimizers. This finding is consistent with the work of Lauritsen and colleagues (1991) who found a positive relation between participation in deviant subsistence strategies and increased risk for victimization.

A strong positive association was found between survival sex and sex- 
ual victimization. Although many street youth report trading sex, often as a means of survival (Kipke et al., 1995; Rotheram-Borus et al., 1992), the risks associated with selling sex are often high. Young people are at risk of being victimized by their customers, pimps, and other street people (Weisberg, 1985). Although youth may be aware of the high risks associated with this behavior, many of them resort to trading sex because they have no other options (Silbert \& Pines, 1981). Since most street youth have few options available when it comes to surviving on the streets, they are likely to continue to be at high risk for sexual victimization.

Although prior research exists on potential risk factors for homeless and runaway youth, the current study provides a more comprehensive understanding of the victimization process by focusing on the direct and indirect effects of such risk factors, which help to tease out linkages between early sexual abuse and later sexual victimization. Another strength of this research is its reliance on a strong theoretical model, which helps to explain how adolescents end up on the street and why they engage in deviant activities once they are out there. Based on a risk amplification model (Whitbeck et al., 1999), the current study suggests that early abuse in the home places these adolescents on trajectories for early independence. The coercive and abusive interaction styles, which adolescents learned within the home, are generalized to other contexts. As such, adolescents are rejected by conventional friends, and seek out new relationships that are "supportive" of such interactions styles, which leads to their involvement with deviant peers. It appears that spending time in the street environment and associating with deviant peers subsequently leads to the adolescent's involvement in risky, deviant behaviors, and such behaviors, either directly or indirectly, lead to an increased risk for sexual victimization.

Some limitations in the present study should be noted. The first is the reliance on cross-sectional data. Although longitudinal data are needed to establish causation, the use of a life course perspective that takes into account early life histories seems promising. In addition, the intervening variables, which are time-delimited variables that help strengthen the causal argument, have significant effects on young people's risk for sexual victimization. Another limitation is respondents' self-reports. Participants were informed however, that their responses would be confidential, and the interviewers were familiar with local street cultures and were already known and trusted by many of the runaways. For these reasons, it is less likely that the respondents would be motivated to bias their responses. Moreover, comparisons done on runaway adolescents and their parents reveal this population does not appear to be overreporting abuse within the home (Whitbeck, Hoyt, \& Ackley, 1997b). Another limitation is the retrospective nature of some of the measures, 
which may have resulted in some over or underreporting. For example, the measure number of times run required youth to think back to all the different times that they had run away from home and some youth offered very high numbers.

Future analyses might examine the extent to which characteristics of the abuse (e.g., duration of the abuse or relation to perpetrator) might influence whether adolescents run from home. In addition, the role of self-esteem and depression might be examined to determine its influence on sexual victimization on the streets. Finally, information on the perpetrators of street victimization is needed since the relation of the perpetrator may be differentially associated with different types of outcomes (e.g., physical versus sexual victimization).

At the policy level, these results have practical implications for those who work with homeless and runaway adolescents. Foremost is the fact that many of these young people have experienced early sexual abuse in the home at the hands of a parent or caretaker. Policies that require runaways to return home may only put these youth at further risk for revictimization by such family members. Additionally, sending youth back home may only increase the risk of these youth running again. A second policy implication has to do with life on the streets for these youth. The results of this study indicate a strong association between affiliating with deviant peers and participating in deviant behaviors with an increased risk for sexual victimization. The pattern of exploitation and victimization within the family and on the streets has serious and cumulative developmental consequences. Early intervention programs, such as safe houses, drop-in centers, and especially street-based outreach workers are needed to break the cycle of exploitation and abuse that adolescents experience within the family and then again on the streets. Without intervention, many of these youth are at risk for remaining on a continuous course of antisocial behavior, thereby becoming "life-course persistent" (Moffitt, 1993).

In summary, young people who leave dysfunctional families to escape abuse often face new sets of problems once they reach the streets. Lacking conventional ties, these youth shuffle back and forth from home to the streets. Associating with friends who engage in deviant behaviors increases the chances that these youth will engage in similar activities. With few legitimate means of support, many youth resort to deviant, risky behaviors as a means of survival. Those who spend more time in the street environment are likely to be exposed to other street people and potential dangers and risks. The combination of the street environment and participation in deviant and risky activities is likely to increase these young peoples' chances of being sexually victimized. 


\section{ACKNOWLEDGMENTS}

A version of this article was presented at the biennial meeting of the Society for Research in Child Development in Albuquerque, New Mexico, April 1999.

The Seattle Homeless Adolescent Research and Education Project (SHARE) is supported by the National Institute on Alcohol Abuse and Alcoholism (AA10253-05), Ana Mari Cauce \& Les B. Whitbeck, investigators.

\section{REFERENCES}

Abbey, A., Ross, L. T., McDuffie, D., \& McAuslan, P. (1996). Alcohol and dating risk factors for sexual assault among college women. Psychology of Women Quarterly, 20, 147-169.

Bagley, C., \& Young, L. (1987). Juvenile prostitution and child sexual abuse: A controlled study. Canadian Journal of Community Mental Health, 6, 5-26.

Beitchman, J. H., Zucker, K. J., Hood, J. E., da Costa, G. A., \& Akman, D. (1991). A review of the short-term effects of child sexual abuse. Child Abuse \& Neglect, 15, 537-556.

Beitchman, J. H., Zucker, K. J., Hood, J. E., da Costa, G. A., Akman, D., \& Cassavia, E. (1992). A review of the long-term effects of child sexual abuse. Child Abuse \& Neglect, 16, 101118.

Browne, A., \& Finkelhor, D. (1986). Impact of child sexual abuse: A review of the research. Psychological Bulletin, 99, 66-77.

Carmines, E. G., \& Zeller, R. A. (1979). Reliability and validity assessment. Sage University paper series on Quantitative Applications in the Social Sciences (Series No. 07-017). Newbury Park, CA: Sage.

Caspi, A., Bem, D. J., \& Elder, G. H. (1987). Moving against the world: Life-course patterns of explosive children. Developmental Psychology, 23, 308-313.

Cauce, A. M., Paradise, M., Embry, L., Morgan, C. J., Lohr, Y., Theofelis, J., Heger, J., \& Wagner, V. (1998). Homeless youth in Seattle: Youth characteristics, mental health needs, and intensive case management. In K. Kutash, A. Duchnowski, \& M. Epstein (Eds.), Communitybased programming for children with serious emotional disturbances: Research and evaluation (pp. 611-632). Baltimore, MD: Brookes Publishing.

Eckenrode, J., Powers, J. L., \& Garbarino, J. (1997). Youth in trouble are youth who have been hurt. In J. Garbarino \& J. Eckenrode (Eds.), Understanding abusive families: An ecological approach to theory and practice (pp. 166-193). San Francisco: Jossey-Bass.

Elder, G. (1998). Life course and human development. In R. Lerner (Ed.), Handbook of child psychology: Vol. 1. Theoretical models of human development (pp. 939-991). New York: Wiley.

Farber, E. D., Kinast, C., McCoard, W. D., \& Falkner, D. (1984). Violence in families of adolescent runaways. Child Abuse \& Neglect, 8, 295-299.

Finkelhor, D. (1984). Child sexual abuse: New theory and research. New York: Free Press.

Finkelhor, D., \& Dziuba-Leatherman, J. (1994). Children as victims of violence: A national survey. Pediatrics, 94, 413-420.

Garbarino, J., Wilson, J., \& Garbarino, A. C. (1986). The adolescent runaway. In J. Garbarino, C. J. Schellenback, \& J. M. Sebes (Eds.), Troubled youth, troubled families: Understanding families at-risk for adolescent maltreatment (pp. 41-54). Hawthorne, NY: Aldine de Gruyter.

Gutierres, S. E., \& Reich, J. W. (1981). A developmental perspective on runaway behavior: Its relationship to child abuse. Child Welfare, 60, 89-94. 
Hagan, J., \& McCarthy, B. (1997). Mean streets: Youth crime and homelessness. New York: Cambridge University Press.

Hindelang, M. J., Gottfredson, M. R., \& Garofalo, J. (1978). Victims of personal crime: An empirical foundation for a theory of personal victimization. Cambridge, MA: Ballinger.

Janus, M., McCormack, A., Burgess, A. W., \& Hartman, C. (1987). Adolescent runaways: Causes and consequences. Lexington, MA: Lexington Books.

Joreskog, K., \& Sorbom, D. (1993). LISREL VIII: User's reference guide. Chicago: Scientific Software.

Kellogg, N. D., \& Hoffman, T. J. (1997). Child sexual revictimization by multiple perpetrators. Child Abuse \& Neglect, 21, 953-964.

Kendall-Tackett, K. A., Williams, L. M., \& Finkelhor, D. (1993). Impact of sexual abuse on children: A review and synthesis of recent empirical studies. Psychological Bulletin, 113, 164-180.

Kipke, M. D., O'Connor, S., Palmer, R., \& MacKenzie, R. G. (1995). Street youth in Los Angeles: Profile of a group at high risk for human immunodeficiency virus infection. Archives of Pediatrics \& Adolescent Medicine, 149, 513-519.

Kipke, M. D., Unger, J. B., O'Connor, S., Palmer, R. F., \& LaFrance, S. R. (1997). Street youth, their peer group affiliation and differences according to residential status, subsistence patterns, and use of services. Adolescence, 32, 655-669.

Lauritsen, J. L., Sampson, R. J., \& Laub, J. H. (1991). The link between offending and victimization among adolescents. Criminology, 29, 265-291.

McCarthy, B., \& Hagan, J. (1992). Surviving on the street: The experiences of homeless youth. Journal of Adolescent Research, 7, 412-430.

McCormack, A., Janus, M., \& Burgess, A. W. (1986). Runaway youths and sexual victimization: Gender differences in an adolescent runaway population. Child Abuse $\mathcal{E}$ Neglect, 10, 387-395.

Moffitt, T. E. (1993). Adolescence-limited and life-course-persistent antisocial behavior: A developmental taxonomy. Psychological Review, 100, 674-701.

Morrow, K. B., \& Sorell, G. T. (1989). Factors affecting self-esteem, depression, and negative behaviors in sexually abused female adolescents. Journal of Marriage and the Family, 51, 677-686.

Patterson, G. R. (1982). Coercive family processes. Eugene, OR: Castilia.

Patterson, G. R., DeBaryshe, B. D., \& Ramsey, E. (1989). A developmental perspective on antisocial behavior. American Psychologist, 44, 329-335.

Patterson, G. R., Dishion, T. J., \& Bank, L. (1984). Family interaction: A process model of deviancy training. Aggressive Behavior,10, 253-267.

Putnam, F. W., \& Trickett, P. K. (1993). Child sexual abuse: A model of chronic trauma. Psychiatry, 56, 82-95.

Rotheram-Borus, M. J., Meyer-Bahlburg, H. F. L., Koopman, C., Rosario, M., Exner, T. M., Henderson, R., Matthieu, M., \& Gruen, R. S. (1992). Lifetime sexual behaviors among runaway males and females. The Journal of Sex Research, 29, 15-29.

Sedlak, A. J., \& Broadhurst, D. D. (1996). Third national incidence study of child abuse and neglect. Rockville, MD: U.S. Department of Health and Human Services.

Silbert, M. H., \& Pines, A. M. (1981). Sexual child abuse as an antecedent to prostitution. Child Abuse \& Neglect, 5, 407-411.

Silbert, M. H., \& Pines, A. M. (1982). Entrance into prostitution. Youth \& Society, 13, 471500.

Terrell, N. E. (1997). Street life: Aggravated and sexual assaults among homeless and runaway adolescents. Youth \& Society, 28, 267-290.

Trickett, P. K., \& Putnam, F. W. (1998). Developmental consequences of child sexual abuse. In P. K. Trickett \& C. J. Schellenbach (Eds.), Violence against children in the family and in the community (pp. 39-56). Washington, DC: American Psychological Association. 
Weisberg, D. K. (1985). Children of the night: A study of adolescent prostitution. Lexington, MA: Lexington Books.

Whitbeck L. B., \& Hoyt, D. R. (1999). Nowhere to grow: Homeless and runaway adolescents and their families. Hawthorne, NY: Aldine de Gruyter.

Whitbeck, L. B., Hoyt, D. R., \& Ackley, K.A. (1997a). Abusive family backgrounds and later victimization among runaway and homeless adolescents. Journal of Research on Adolescence, 7, 375-392.

Whitbeck, L. B., Hoyt, D. R., \& Ackley, K. A. (1997b). Families of homeless and runaway adolescents: A comparison of parent/caretaker and adolescent perspectives on parenting, family violence, and adolescent conduct. Child Abuse \& Neglect, 21, 517-528.

Whitbeck, L. B., Hoyt, D. R., \& Yoder, K. A. (1999). A risk-amplification model of victimization and depressive symptoms among runaway and homeless adolescents. American Journal of Community Psychology, 27, 273-296.

Whitbeck, L. B., \& Simons, R. L. (1990). Life on the streets: The victimization of runaway and homeless adolescents. Youth \& Society, 22, 108-125.

Whitbeck, L. B., \& Simons, R. L. (1993). A comparison of adaptive strategies and patterns of victimization among homeless adolescents and adults. Violence and Victims, 8, 135-152.

Widom, C. S., \& Kuhns, J. B. (1996). Childhood victimization and subsequent risk for promiscuity, prostitution, and teenage pregnancy: A prospective study. American Journal of Public Health, 86, 1607-1612.

Wright, J., Allen, T. L., \& Devine, J. (1995). Tracking non-traditional populations in longitudinal studies. Evaluation and Program Planning, 18, 267-277.

Yates, G. L., MacKenzie, R., Pennbridge, J., \& Cohen, E. (1988). A risk profile comparison of runaway and non-runaway youth. American Journal of Public Health, 78, 820-821. 